\title{
Crystal structures of commercial pharmaceuticals
}

\author{
James A. Kaduk ${ }^{a}$, Zachary R. Butler ${ }^{a}$, Partha P. Das ${ }^{b}$, Amy M. Gindhart ${ }^{c}$, and Thomas N. \\ Blantonc, kaduk@polycrystallography.com \\ ${ }^{a}$ North Central College, 131 S. Loomis St., Naperville IL 60540 \\ bNanomegas, Brussels, Belgium, partha@nanomegas.com \\ ICDD, 12 Campus Blvd., Newtown Square PA 19073, gindhart@icdd.com, tblanton@icdd.com
}

As part of a continuing project, the challenging room-temperature crystal structures of six commercial pharmaceutical APIs have been solved by Monte Carlo simulated annealing techniques using synchrotron X-ray powder diffraction data (11-BM at APS), and optimized using density functional techniques. Bisoprolol fumarate, $\left(\mathrm{C}_{18} \mathrm{H}_{33} \mathrm{NO}_{4}\right)_{2}\left(\mathrm{C}_{4} \mathrm{H}_{2} \mathrm{O}_{4}\right)$, crystallizes in $P 1$, with $a=$ 8.16570(5), $b=8.51639(12), c=16.75179(18) \AA, \alpha=89.142(1), \beta=78.155(1), \gamma=81.763(1)^{\circ}, V$ $=1128.265(10) \AA^{3}$, and $Z=1$. The structure was difficult to solve because the two ends of the bisoprolol cation are similar but not identical. Hyoscyamine sulfate monohydrate, $\left(\mathrm{C}_{17} \mathrm{H}_{24} \mathrm{NO}_{3}\right)_{2}\left(\mathrm{SO}_{4}\right)\left(\mathrm{H}_{2} \mathrm{O}\right)$, (generally described as a dihydrate) crystallizes in $P 2_{1}$ with $a=$ 6.60196(2), $b=12.95496(3), c=20.93090(8) \AA, \beta=94.8839(2)^{\circ}, V=1783.680(5) \AA^{3}$, and $Z=2$. The multiple fragments led to a low success rate. Atropine sulfate monohydrate, $\left(\mathrm{C}_{17} \mathrm{H}_{24} \mathrm{NO}_{3}\right)_{2}\left(\mathrm{SO}_{4}\right)\left(\mathrm{H}_{2} \mathrm{O}\right)$, (racemic hyoscyamine) crystallizes in $P 2_{1} / n$ with $a=19.2948(5), b=$ 6.9749(2), $c=26.9036(5) \AA, \beta=94.215(2)^{\circ}, V=3610.86(9) \AA^{3}$, and $Z=4$. The success rate of solution using DASH was only $1 \%$, and required Mogul Distribution Bias and $\{010\}$ preferred orientation. Despite being apparently orthorhombic cefprozil monohydrate, $\mathrm{C}_{18} \mathrm{H}_{19} \mathrm{~N}_{3} \mathrm{O}_{5} \mathrm{~S}\left(\mathrm{H}_{2} \mathrm{O}\right)$, crystallizes in $P 2$, with $a=11.26503(5), b=11.34017(4), c=14.72628(10) \AA, \beta=90.1249(4)^{\circ}, V$ $=1881.24(2) \AA^{3}$, and $Z=4$. DFT calculations suggest that the carboxylic acid proton on one (but not the other) of the two independent cefprozil molecules is transferred to an amino group, forming a salt. This suggestion needs to be confirmed by spectroscopic experiments and calculations of the vibrational spectrum. Despite being apparently monoclinic, metolazone, $\mathrm{C}_{16} \mathrm{H}_{16} \mathrm{ClN}_{3} \mathrm{O}_{7}$, crystallizes in $P 1$ with $a=8.1976(5), b=14.4615(69), c=16.0993(86) \AA, \alpha=115.009(18), \beta=$ 90.096(7), $\gamma=106.264(4)^{\circ}, V=1644.52(9) \AA^{3}$, and $Z=4$. The broad 021 peak indicates stacking faults in the structure. Linagliptin, $\left(\mathrm{C}_{25} \mathrm{H}_{28} \mathrm{~N}_{8} \mathrm{O}_{2}\right)_{2}$ (solvent) $\left(\mathrm{H}_{2} \mathrm{O}\right)$, crystallizes in $\mathrm{P} 2{ }_{1}{ }_{1} 2$ with $a=$ 24.85078(12), $b=21.5691(8), c=9.74377(4) \AA, V=5222.77(3) \AA^{3}$, and $Z=8$. The structure was solved by TEM electron tomography. Initial fit to the X-ray powder data was relatively poor, but the structure contains a channel, which is filled with water and solvent. Hydrogen bonding is important in all these crystal structures. 